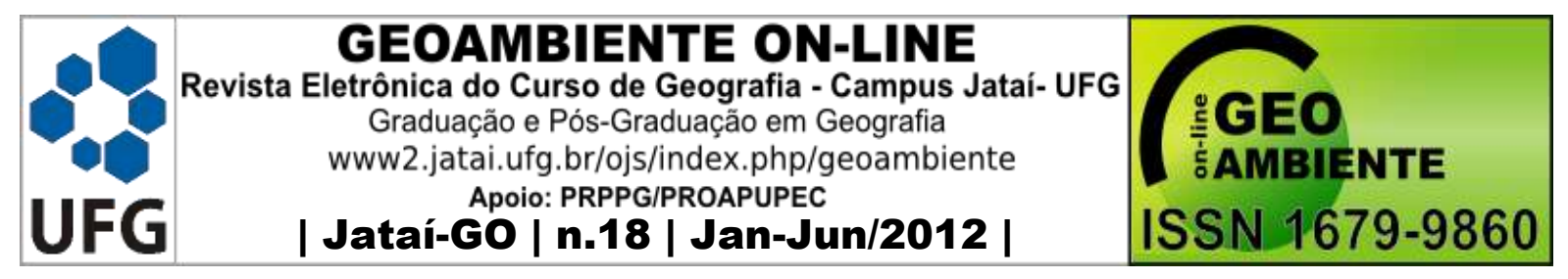

\title{
ANÁLISE DO USO E OCUPAÇÃO DO SOLO NO ASSENTAMENTO SANTO ANTÔNIO NO MUNICÍPIO DE CAJAZEIRAS-PB
}

\author{
Janierk Pereira de Freitas ${ }^{1}$, Manoel Ferreira da Silva NETO² ${ }^{2}$, Francisco Eduardo de \\ FREITAS $^{2}$, Erika Juliana LINHARES ${ }^{3}$, Monalisa Cristina Silva Medeiros ${ }^{4}$.
}

(1 - Universidade Federal de Campina Grande - UFCG, Mestranda em Recursos Naturais pela - UFCG, Janierk_pfreitas@ hotmail.com, Rua Epitácio Pessoa, 245 apt.102. Centro. Campina Grande- PB, 2 - Universidade Federal de Campina Grande, Graduando Bacharelado em Química Industrial pela Universidade Federal da Paraíba- UFPB, manoelferreira.ufpb@gmail.com. Graduado em Historia pela Universidade Federal de Campina Grande - UFCG,eduardoefreitas@hotmail.com 3 - Universidade Federal de Campina Grande, Bacharelada em Direito pela Universidade Federal de Campina Grande UFCG herikajuliana@hotmail.com, Mestranda em Recursos Naturais pela - UFCG, 4 Universidade Federal de Campina Grande - UFCG, Mestranda em Recursos Naturais pela UFCG, Graduada em Geografia pela Universidade Estadual da Paraíba UEPB,monalisacristinasm@ hotmail.com)

\section{RESUMO}

O presente artigo tem como objetivo analisar o atual uso e ocupação do solo e as atividades agrícolas desenvolvida pelos agricultores do assentamento Santo Antonio no Município de Cajazeiras - PB. Verificando que meios esses agricultores vem utilizando para que esta terra seja produtiva ao longo dos anos e quais os plantios são mais adaptados ao solo do assentamento. O procedimento metodológico utilizou-se dos pressupostos da pesquisa qualitativa.A coleta de dados foi realizada a partir de entrevistas semiestruturadas,depoimento de agricultores e familiares tendo uma abordagem quantitativa na sistematização de parte dos dados, sendo compilados em gráficos. Aliado a estas, utilizou-se a metodologia denominada "bola de neve" na qual os primeiros entrevistados, indicam outros atores sociais, e assim

Artigo recebido para publicação em 03 de Dezembro de 2011

Artigo aprovado para publicação em 25 de Maio de 2012 


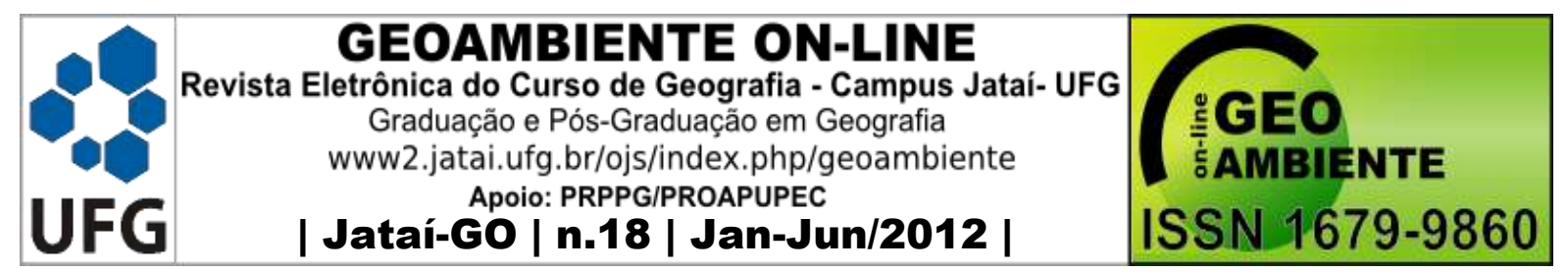

sucessivamente. De acordo com as informações obtidas pelos participantes da pesquisa, os resultados mostraram que os agricultores vem se adaptando de novos mecanismo para uma nova lógica e concepção de trabalhar e construir um Semiárido com práticas agrícolas saudáveis voltadas para a preservação ou recuperação do solo degradado garantido assim à preservação dos recursos naturais e melhoria na qualidade de vida dos mesmos.

Palavras-chave: Agricultores, Solo, Atividades Agrícolas, Preservação dos Recursos Naturais.

\section{ABSTRACT \\ ANALYSIS OF THE USE AND OCCUPANCY OF LAND SETTLEMENT IN THE MUNICIPALITY OF SANTO ANTONIO CAJAZEIRAS-BRAZIL}

This article aims to analyze the current use and occupation of land and agricultural activities developed by the farmers of the settlement in the municipality of SantoAntonio Cajazeiras - PB. Noting that means these farmers have been using this land to be productive over the years and what crops are best adapted to soilsettlement. The methodological approach we used the assumptions of the research qualitativa.A data collection was carried out through interviews,testimony of farmers and their families with a quantitative approach to the systematization of the data being compiled into graphs. Allied to this, we used amethodology called "snowball" in which the first respondents indicate other social actors, and so on. According to information obtained by the research participants, the results showed that farmers has adapted a new mechanism for a new logicand design work and build a Semiarid with healthy farming practices aimed atconserving or restoring degraded soil thus ensuring the conservation of natural resources and improvement in quality of life for them.

Keywords: Farmers, Land, Agricultural Activities, Conservation of Natural Resources.

\section{RESUMEN}

\section{ANÁLISIS DEL USO Y OCUPACIÓN DEL SUELO EN EL ASENTAMIENTO SANTO ANTÔNIO EN EL MUNICIPIO DE CAJAZEIRAS-BRASIL}

En este artículo se pretende analizar el uso actual y la ocupación de las actividades terrestres y agrícolas desarrolladas por los agricultores del asentamiento en el municipio de Santo Antonio Cajazeiras - PB. Tomando nota de que significa que estos agricultores han 


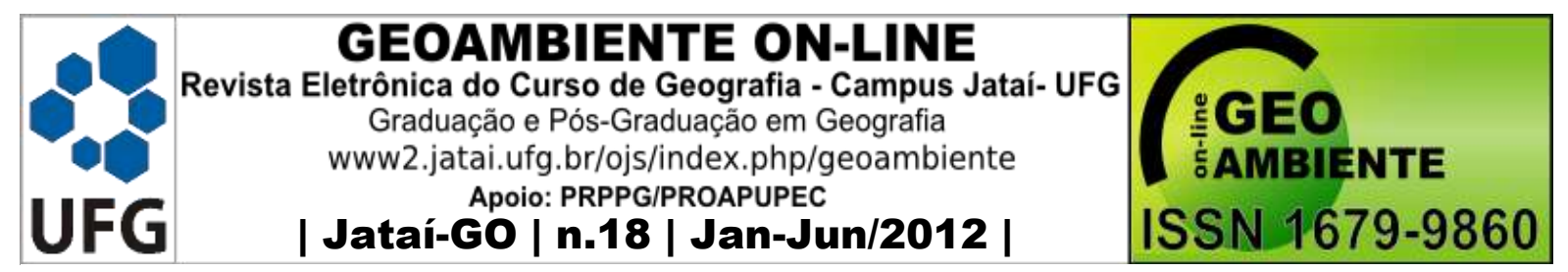

estado utilizando esta tierra para ser productivos durante los años y qué cultivos se adaptan mejor a la solución del suelo. El enfoque metodológico que utiliza los supuestos de la colección de investigación qualitativa.A de datos se llevó a cabo a través de entrevistas, testimonios de los agricultores y sus familias con un enfoque cuantitativo para la sistematización de los datos que se compilan en los gráficos. Junto a esto, se utilizó una metodología llamada "bola de nieve" en el que los primeros en responder indican otros actores sociales, y así sucesivamente. De acuerdo coninformación obtenida por los participantes en la investigación, los resultados mostraron que los agricultores se ha adaptado un nuevo mecanismo para una nueva lógica y el trabajo de diseño y construcción de un Semiárido con prácticas agrícolas saludables dirigidos a la conservación de los suelos degradados o la restauración de lo que garantiza la conservación de los recursos naturales y la mejora de la calidad de vida para ellos.

Palabras clave: Agricultores, la tierra, las actividades agrícolas, conservación de recursos naturales.

\section{INTRODUÇÃO}

Um dos principais desafios da civilização contemporânea consiste na geração de mecanismos capazes de harmonizar as relações da sociedade humana com o meio ambiente. A agricultura foi o ponto crucial para o inicio das civilizações humana. Sendo esta atividade um fator predominante para a economia das civilizações por muitos anos até a chegada da Revolução Industrial que traz uma nova roupagem para agricultura, a chamada agricultura moderna de meados do Século XVIII e XIX, considerada como primeira revolução agrícola, caracterizada pelos sistemas de rotação e associação de atividades agrícolas e pecuárias.

Hoje a agricultura apresenta-se mecanizada, que utiliza técnicas extremamente sofisticadas como uso de fertilizantes, sistemas de irrigação adequados às culturas, correção dos solos, atribuindo lhes produtos químicos para corrigir as suas características, uso de estufas e seleção de sementes. A segunda revolução agrícola chamada de "Revolução Verde," culminou na década de 1970 movimentos que intencionava aumentar a produtividade, mas terminou por provocar sério passivo ambiental como; destruição das florestas, erosão dos solos, contaminação dos recursos naturais dos alimentos e provocados sérios conflitos sociais (aumento da concentração da posse de terra, êxodo rural e desemprego) (PEREIRA, 2005). 


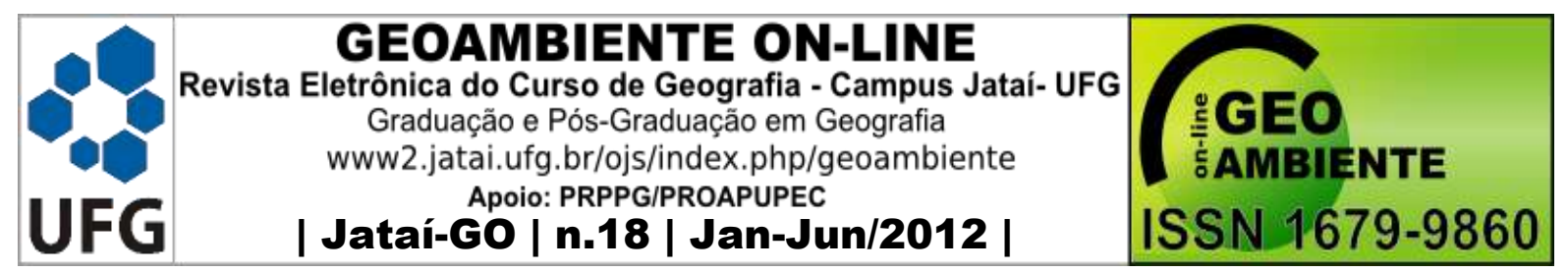

A modernização da agricultura, cultivos com a utilização de máquinas e o uso intenso dos solos, têm promovido mudanças drásticas no comportamento dos atributos físicos do solo o que, conseqüentemente, influencia a produção, o equilíbrio dos recursos naturais e a dinâmica da água no solo (Gomes et al., 2007).

Segundo MOTA (1995, p. 109), o uso e a ocupação do solo em determinadas áreas devem considerar os aspectos naturais do meio físico que possam ter influência sobre os recursos hídricos. Estes condicionamentos devem ser estudados em conjunto, de modo a garantir o uso e a ocupação da área evitando o máximo possível de mudanças ambientais. As mudanças ambientais podem influenciar nas características físicas e naturais da área com mudança de microclima.

Práticas de manejo como pousio, desmatamento e queima da vegetação nativa já não são considerados eficazes para recuperação ou recomposição da fertilidade, do solo, métodos estes que já foi considerado adequado quando o homem do campo disponibilizava de uma maior quantidade de terra em que uma área ficava descansando até recuperar sua fertilidade. Hoje o acesso a terra se tornou mais limitado para os pequenos produtores devido a intensificação da agricultura mecanizada. Obrigando assim o pequeno produtor a procurar manejos adequados de como utilizar o mesmo solo sem que o mesmo perca sua fertilidade.

Baseado nesse contexto que a agricultura convencional sempre se apresentou como uma ameaça a biodiversidade e até mesmo ao futuro da produção agrícola, surgem novos modelos de produção agrícola que podem ao mesmo tempo garantir a sustentabilidade do sistema, e rendimentos econômicos. São praticas agrícolas diferenciadas, denominadas alternativas que rejeitam as técnicas e métodos do sistema convencional de produção. Uma dessas alternativas que vem sendo destacadas dentro do contexto de uma agricultura sustentável é a Agroecologia, pois além, de produzir sem agrotóxicos,trabalha com o manejo ecológico dos agroecossistema priorizando assegurar a fertilidade contínua dos solos. Encontra-se destinada á subsistência e à qualidade de vida do pequeno produtor rural e de sua família, não deixando de lado a inserção dos seus produtos agroecológicos num mercado que é cada vez maior e atua com relações mais solidárias.

O assentamento Santo Antônio, no município de Cajazeiras/PB localiza-se na porção leste do município nas coordenadas geográficas $6^{\circ} 53^{\prime}$ de latitude Sul e $38^{\circ} 23^{\prime}$ de Longitude Oeste integrando o extremo Oeste do Estado, sentido Cajazeiras- Sousa, através da BR-230. O clima predominante é definido, de acordo com a classificação de Koppen, como Awig, 


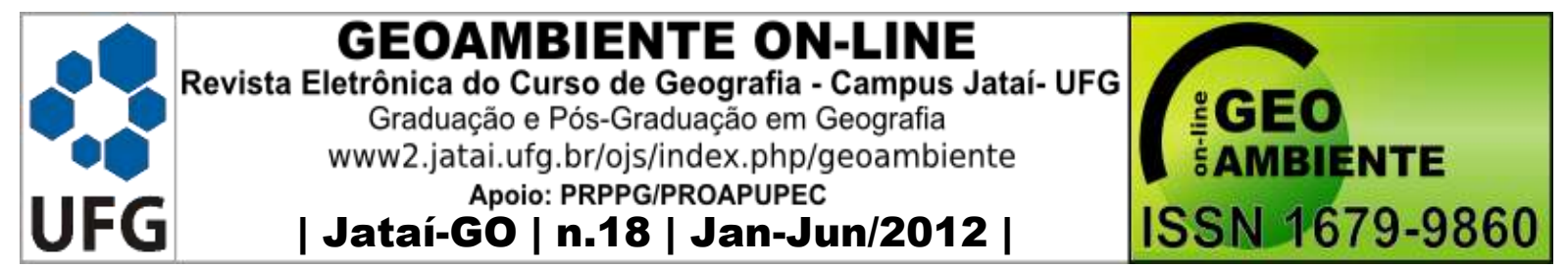

denominado de clima tropical chuvoso, com pequena variação de temperatura média anual, ocorrendo precipitações de forma expressiva nos meses de janeiro, fevereiro, março e abril. A temperatura varia entre as médias de $24^{\circ} \mathrm{C}$ e $29^{\circ} \mathrm{C}$, com uma amplitude térmica em torno de $5^{\circ}$ C. Os meses mais frios correspondem a junho e julho e os mais quentes são outubro, novembro e dezembro (IBGE, 2011).

A fazenda Santo Antônio foi desapropriada pelo o INCRA em 1997, tornando-se o primeiro assentamento rural da microrregião de Cajazeiras, e foi um marco inicial do processo de desapropriação em outras comunidades rurais do sertão. Diferentemente de outros assentamentos, as 32 famílias assentadas na Fazenda Santo Antonio já viviam nas suas dependências, na condição de trabalhadores rurais, ocorrendo no Assentamento à permanência dessas famílias, e não a ocupação do lugar por trabalhadores vindos de outras localidades, como na maioria dos demais assentamentos rurais. Assim ocorrendo a permanência desses pequenos produtores na área após ser desapropriada passando por adaptações e conflitos à nova realidade, ao passarem de meeiros para proprietários da terra.

O objetivo geral deste artigo é pesquisar como essas famílias vêem utilizando e ocupando o solo e quais as práticas agrícolas desenvolvidas pelos estes agricultores.

Para entendermos o uso e ocupação do solo o presente trabalho buscou aporte em alguns autores como; MOLLE (1994), MOTA (1995), GUERRA \& CUNHA (1995 187), MELO (1988), PRIMAVESI (2006), PETERSEN (et., al 2002), TITTONEL (et. ,al 2008), CAPORAL (2009), BEDUSCHI FILHO( 2003), ALTIERI E YURIEVICH (1991), ANDRADE (2005) e outros que contribuíram com suas idéias e discussão sobre o tema proposto.

\section{UM BREVE RESGATE HISTÓRICO DA OCUPAÇÃO E EXPLORAÇÃO DO SOLO BRASILEIRO}

A formação e a organização do território brasileiro se deu com base na posse de grandes extensões de terra, doadas a quem se habilitasse a explorá-la, causando grandes impactos socioambientais.Nesse sentido podemos compreender que o problema da degradação ambiental no Brasil está diretamente inserido neste processo de exploração demasiado dos recursos naturais, implementado desde o período de colonização, ligado à orientação e aos interesses políticos e econômicos que determinam a ocupação e o uso desse espaço territorial. 


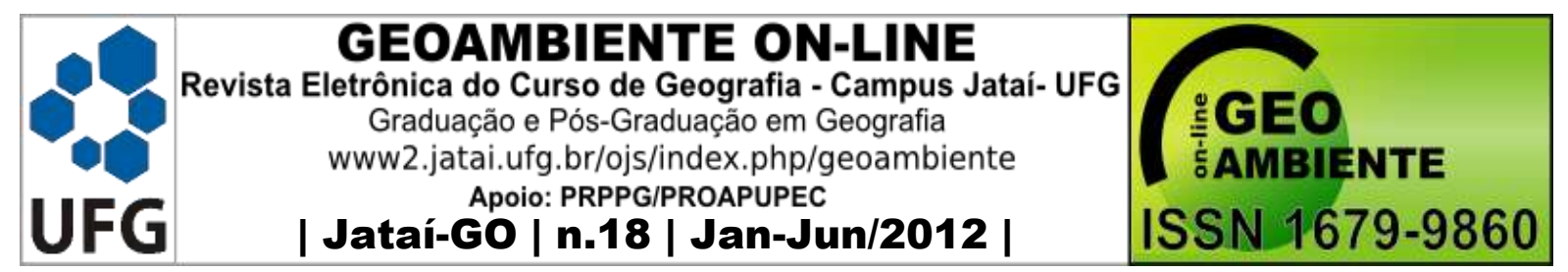

A região do Sertão Paraibano foi ocupada, inicialmente, por desbravadores que vinham em busca de áreas de pastagens para a criação de gado extensiva, principalmente nas margens de rios e riachos Segundo ANDRADE (2005) o sertão nordestino foi ocupado pela expansão da pecuária extensiva e da lavoura algodoeira em campo aberto às custas da destruição da caatinga e das nações indígenas. Atualmente, com a decadência da lavoura algodoeira, uma das formas de ocupação e utilização do solo é a pecuária extensiva e a agricultura de subsistência. A fragilidade dos solos e ausência de medidas conservacionistas esgotou rapidamente o potencial produtivo das terras, passando a predominar a pecuária leiteira como atividade que, além de ser mais adaptável aos solos pobres, consolidando os grandes latifúndios na região (BEDUSCHI FILHO, 2003).

Não faz muito tempo, o Sítio Santo Antonio era uma área inteiramente coberta por vegetação nativa de valor biótico singular. Prova disso é que a remanescente vegetação da caatinga ainda abriga rica e importante biodiversidade. Como também o ambiente aquático através de açude e barragens mantém as qualidades favoráveis ao desenvolvimento de vidas e uso pela comunidade local. Para os assentados, a água e a terra significam trabalho e garantia de permanência na região.

O modelo hegemônico, que regi o desenvolvimento rural e agrícola no Brasil desde a segunda guerra mundial, está dando mostras de crise e esgotamento. Isto se deve não apenas aos limites de disponibilidade dos recursos naturais do qual é dependente, como também devido ao acelerado consumo, queima, destruição e degradação dos recursos naturais renováveis e não renováveis necessários para sua reprodução. Tal modelo, ainda dominante nas orientações de política pública, foi e continua sendo responsável por um processo permanente de exclusão social, êxodo rural, diferenciação social e concentração da posse da terra, conseqüências do modelo de desenvolvimento. Neste contexto, a agricultura, subordinada ao poder monopolista de setores agroindustriais, transformou-se profundamente. Camponeses e indígenas foram atropelados pela magnitude dos processos de "modernização conservadora" impulsionados por enormes quantidades de recursos públicos e privados. (Caporal, 2009).

Durante décadas foi colocado para os agricultores que eles precisavam de assistência técnica para manejar e recuperá-los seus solos, já que eles por si só era incapazes de interpretar ou realizar análise das condições físicas dos mesmos. Sendo este o caminho pelo o 


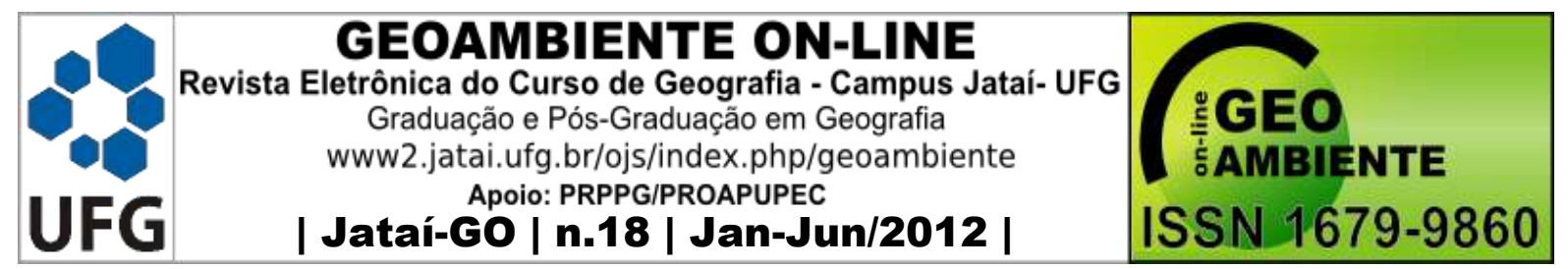

qual levaram os mesmos a adquirir insumos químicos, máquinas, tornando esses agricultores co-financiadores da mecanização da agricultura e ao mesmo tempo fez com que eles perdesse a credibilidade em todo o seu conhecimento adquirido pelas suas experiências de vida, de observação da natureza ao longo dos anos(PRIMAVESI,2008).

\subsection{A AGRICULTURA ORGÂNICA COMO ALTERNATIVA DE MANEJO SADIO PARA O SOLO E COMO BASE ECOLÓGICA PARA A SUSTENTABILIDADE DE COMUNIDADES RURAIS.}

As variedades de climas, solos, plantas, etnias e culturas, a abundância de terras, de água e de energia solar, nos leva a afirmar que é possível implantar novas estratégias de desenvolvimento rural e outros modelos de agriculturas, mais sustentáveis e menos dependentes de insumos químicos. Isso exigirá, entretanto, escolhas políticas e projetos coerentes com essas, alicerçados em estratégias que visem a construção de mais sustentabilidade socioambiental nas atividades agropecuárias. O modelo que regi de uma agricultura totalmente dependente de recursos naturais escassos, não terá sustentabilidade no tempo, pelo simples fato de que os recursos dos quais depende tendem a apresentar redução na oferta e inviabilidade econômica para o seu uso ou mesmo a acabar dado o acelerado ritmo de extração (Caporal, 2009).

No Semiárido nordestino, a Agricultura orgânica é apontada como um novo caminho para a construção de agricultura de base ecológica ou sustentável. Para os agricultores a agroecologia prega as técnicas simples muitas delas já conhecidas pelos o homem do campo, um plantio diversificado, sem utilização de insumos químicos e o uso desmedido da mecanização que agride e danifica o solo, procura promover uma lavoura sustentável com base na dinâmica da natureza permitindo assim a restauração da mesma, significa mais alimento, trabalho e renda no campo, incentiva o associativismo dos produtores e aponta novos canais de comercialização desses produtos, permitindo boas colheitas agora e no futuro.

A chave crucial para essa mudança está diretamente ligada ao solo, é nele que a luz do sol, a água os nutrientes e os recursos abióticos do ecossistema, se integram para gerar a vida. Pois o solo é um organismo vivo, dinâmico que interagem com a biodiversidade para produzir a vida, para que isto aconteça só dependem do seu bom manejo PETERSEN (et,al.,2008). Nesse aspecto, PRIMAVESI (2008) afirma que: 


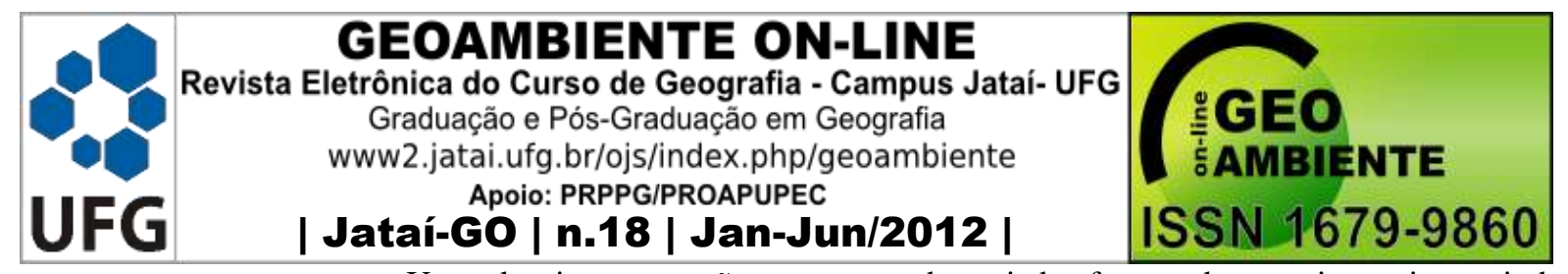

Um solo vivo pressupõe a presença de variadas formas de organismos interagindo ente si e com os componentes minerais e orgânicos do solo. Essa dinâmica biológica exerce uma função essencial na agregação do solo, de modo a torná-lo grumoso e permeável para o ar e para a água. Além disso, são esses organismos que mobilizam os nutrientes e os disponibilizam para as plantas.

Nesse sentido, Cardoso 2008) corrobora:

Ao realizar a interface entre a litosfera e a biosfera, os solos são ambientes onde processos biogeoquímicos transformam água, nutrientes e radiação solar em vida. A litosfera é composta pelas as rochas que estão abaixo do solo e que lhes dão origem. A biosfera é formada por organismos que vivem no solo e acima dele. São todos, direta ou indiretamente, originados a partir de processos do solo que transformam elementos simples como; água, nutrientes e energia em vida.

A necessidade de combater a miséria rural na perspectiva de regenerar a base dos recursos das pequenas propriedades tem levado diversas Organizações Não-Governamentais (ONGs), de países em desenvolvimento, a implementar novas estratégias de desenvolvimento e manejo de recursos na agricultura. Estas ONGs trabalham na perspectiva que o desenvolvimento agrícola deve operar baseados em uma abordagem "de baixo para cima", e que utilize dos recursos que estão disponíveis, a população local, suas necessidades e aspirações, seu conhecimento agrícola e recursos naturais autóctones. A produtividade aumenta na medida em que as estratégias se baseiam na participação, capacidades dos recursos locais, enquanto conservam a base dos recursos. $\mathrm{O}$ conhecimento dos agricultores através de suas experiências vivenciadas no o ambiente ao longo dos anos sobre, plantas, solos e processos ecológicos possui uma grande importância nesse novo paradigma agroecológico. As ONGs que trabalha com programas de desenvolvimento rural (PDR) vem mostrando uma capacidade única de compreender a natureza específica e diferenciada, promovendo experiências de sucesso na geração, com a transferência de tecnologias camponesas. Um elemento-chave tem sido o desenvolvimento de novos métodos agrícolas baseados em princípios agroecológicos, que se assemelham ao processo de produção camponês (Altieri, 2004).

\section{PROCEDIMENTOS METODOLÓGICOS}




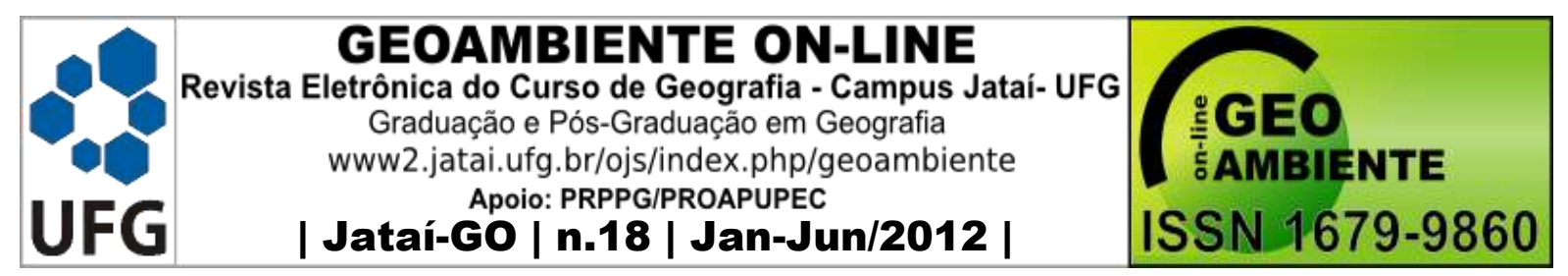

A pesquisa visa analisar o uso e ocupação do solo pelo os moradores do Assentamento Santo Antonio no município de Cajazeiras - PB. Utilizou-se dos pressupostos da Pesquisa qualitativa a qual se caracteriza como um entendimento dos significados e características de uma situação apresentada pelos entrevistados, onde o pesquisador busca compreender os fenômenos, segundo a perspectiva dos atores sociais da situação estudada (BONIFÁCIO, 2008). A coleta de dados foi realizada a partir de entrevistas semiestruturadas, depoimento de agricultores e familiares tendo uma abordagem quantitativa na sistematização de parte dos dados, sendo compilados em gráficos. Aliado a estas, utilizou-se a metodologia denominada "bola de neve", (BIERNACKI; WALDORF, 1981), na qual é possível solicitar aos primeiros entrevistados, a indicação de outros atores sociais, que por sua vez indicam outros, e assim sucessivamente (SOUZA, 2009).

As técnicas de coleta de dados foram divididas em três etapas;

1) A primeira foi a Observação Participante a qual pode ser definida como "uma estratégia de campo que combina ao mesmo tempo a participação ativa com os sujeitos, a observação intensiva em ambientes naturais, entrevistas abertas informais e análise documental (p. 52)" (MOREIRA, 2004);

2) A segunda foi Entrevistas Semi-estruturadas as quais fornecem uma boa amostragem da população geral, uma vez que, o entrevistado não precisa saber ler ou escrever. Há uma maior flexibilidade, permitindo ao entrevistador repetir ou esclarecer as perguntas, bem como possibilita a oportunidade de avaliar atitudes e condutas a partir da observação e registro de reações e gestos. Permite também que os dados sejam quantificados e submetidos a tratamento estatístico (MARCONI; LAKATOS, 2005).

3) A terceira etapa caracterizou-se pela análise e interpretação dos dados coletados.

Desta forma, foram utilizados os seguintes procedimentos teório-práticometodológicos: Pesquisa bibliográfica e documental - periódicos, dissertações, livros, jornais, atas; Levantamento cartográfico referentes à hidrografia, geomorfologia e cobertura vegetal da área estudada. Em seguida, as atividades de campo, que compreenderam os exercícios realizados no período entre Janeiro/2012 à Fevereiro/2012. Na pesquisa de campo foram utilizados: câmera fotográfica; caderno de campo; MP4 e celular para gravação das entrevistas. Também foi realizada caminhada exploratória com a presença de alguns moradores na referida área, para o reconhecimento do arranjo sócio-ambiental da comunidade 


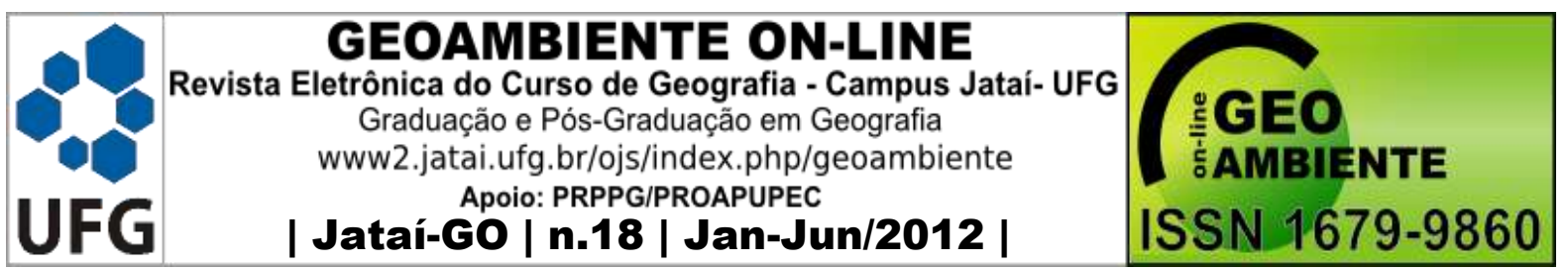

e averiguação de como se encontra o solo no tocante; (erosão, desmatamento, queimadas) a área plantada pelos moradores, se utiliza o solo das margens do açude no período de estiagem para criação de animais e cultivo de vazante se há utilização de agrotóxico ou não nessas plantações, se ocorreu mudanças na maneira de trabalhar a agricultura, como os mesmos fazem para minimizar os danos causados ao solo e o ambiente em geral e quais as dificuldades enfrentadas. O universo amostral dos pesquisados totalizou 15 entrevistados, as entrevistas seguiram um roteiro comum a todos entrevistados. A escolha de um número reduzido de entrevistados é respaldado considerando que, na pesquisa qualitativa o critério crucial não é numérico, onde que uma amostra ideal é aquela capaz de refletir a totalidade nas suas múltiplas dimensões, de maneira a privilegiar os sujeitos sociais que detêm os atributos, os quais o investigador pretende conhecer (MINAYO, 1998; FEITOSA, 2000).

\section{ANALÍSE DOS RESULTADOS}

Com a pesquisa de campo foram revelados os múltiplos usos do solo pelo os moradores da comunidade pesquisada. Antes de iniciarmos a discussão descrevemos um rápido perfil dos entrevistados. Quanto ao percentual dos pesquisados homens e mulheres houve uma predominância do sexo masculino. Em relação à faixa etária observa-se uma predominância dos entrevistados das idades, de 40 a 60 anos como é ilustrado no gráfico 1 .

Gráfico 1.Percentual de homens, mulheres e faixa etária dos entrevistado

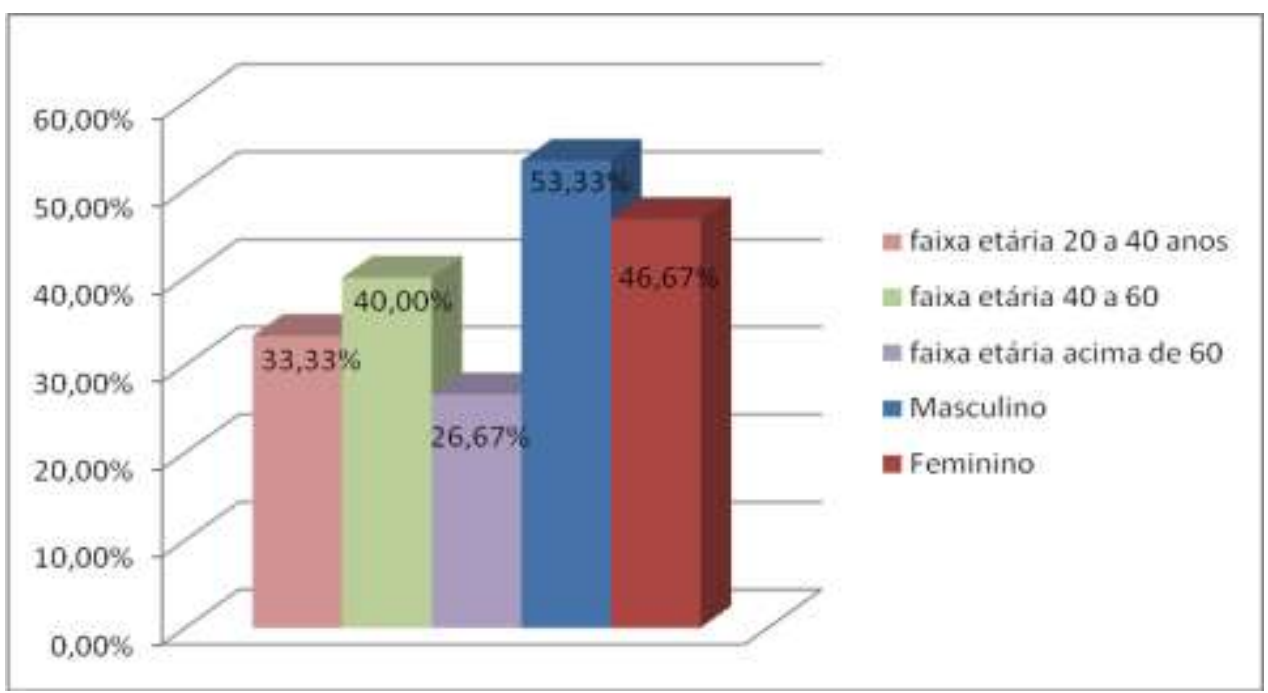

Fonte:Elaboração própria,2012 


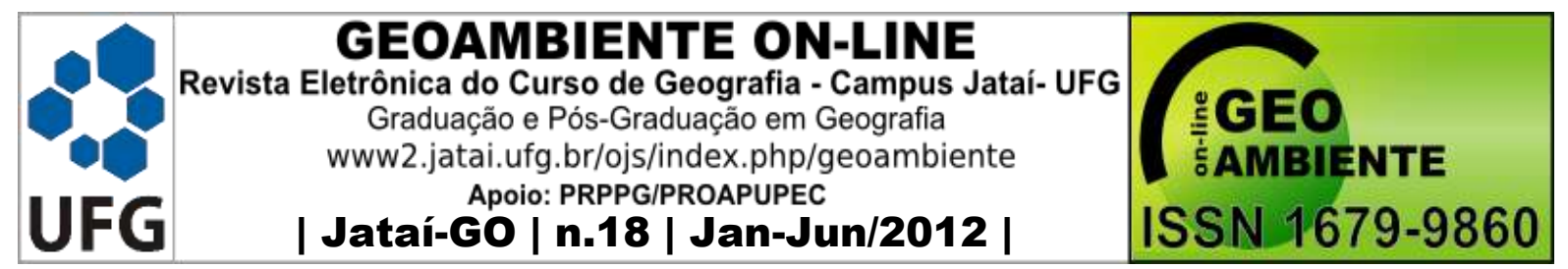

No gráfico 2 refere-se ao manejo e preparo do solo para o plantio, o que foi observado durante a pesquisa é que os agricultores estão deixando a prática antiga da agricultura convencional de desmatar e queimar apesar que isto pode está relacionado a proibição do IBAMA(Instituto Brasileiro do Meio Ambiente e dos Recursos Naturais Renováveis) e da SUDEMA( Superintendência de Administração do Meio Ambiente), que após assentamento intensificou a fiscalização a comunidade, mas a maioria já concorda com a proibição e por isso só desmata o que é permido e não queima muitos reaproveita os mesmo solo descobertos.

\begin{abstract}
Não precisa brocar todos os anos, eu só mando passar o trator nas terras já decoberta e pronto é só plantar e esperar as chuvas, não precisa de mais nada, veneno faz muito tempo que usei a gente tem reunião com a associação local e a CAAASP e eles nos orienta para a gente não usar e mostra vidío do mau que o veneno causa, antes a gente não sabia e invenenava a roça para nós mesmo comer( agricultora, 47 anos, sempre morou na comunidade).
\end{abstract}

Outro agricultor, de 76 anos, sempre foi morador da comunidade complementa:

\begin{abstract}
Eu envenenava a roça para eu mesmo comer e hoje sem veneno nenhum esse quintal tenhe de tudo, eu tenho mandala e planto o ano todo feijão, macaxeira, batata, gerimum, alface, coentro,tem pé de laranja, tangerina, graviola, coco, rumã tem até morango e é tudo natural a gente tem que apreender a trabalhar não é só escutar os enssinamentos nas reuniões com os técnicos, temos que por isso em prática e isso eu faço.
\end{abstract}

\footnotetext{
${ }^{1}$ Brocas: Corte de arbustos ou matos, preparando o terreno para roça (MICHAELIS, 1998, p. 360).

${ }^{2}$ CAAASP (Associações dos Assentamentos do Alto Sertão Paraibano presta assessoria técnica aos Assentamentos do alto sertão paraibano).
}

Gráfico 2.Manejo e Preparo do solo para os Cultivos 


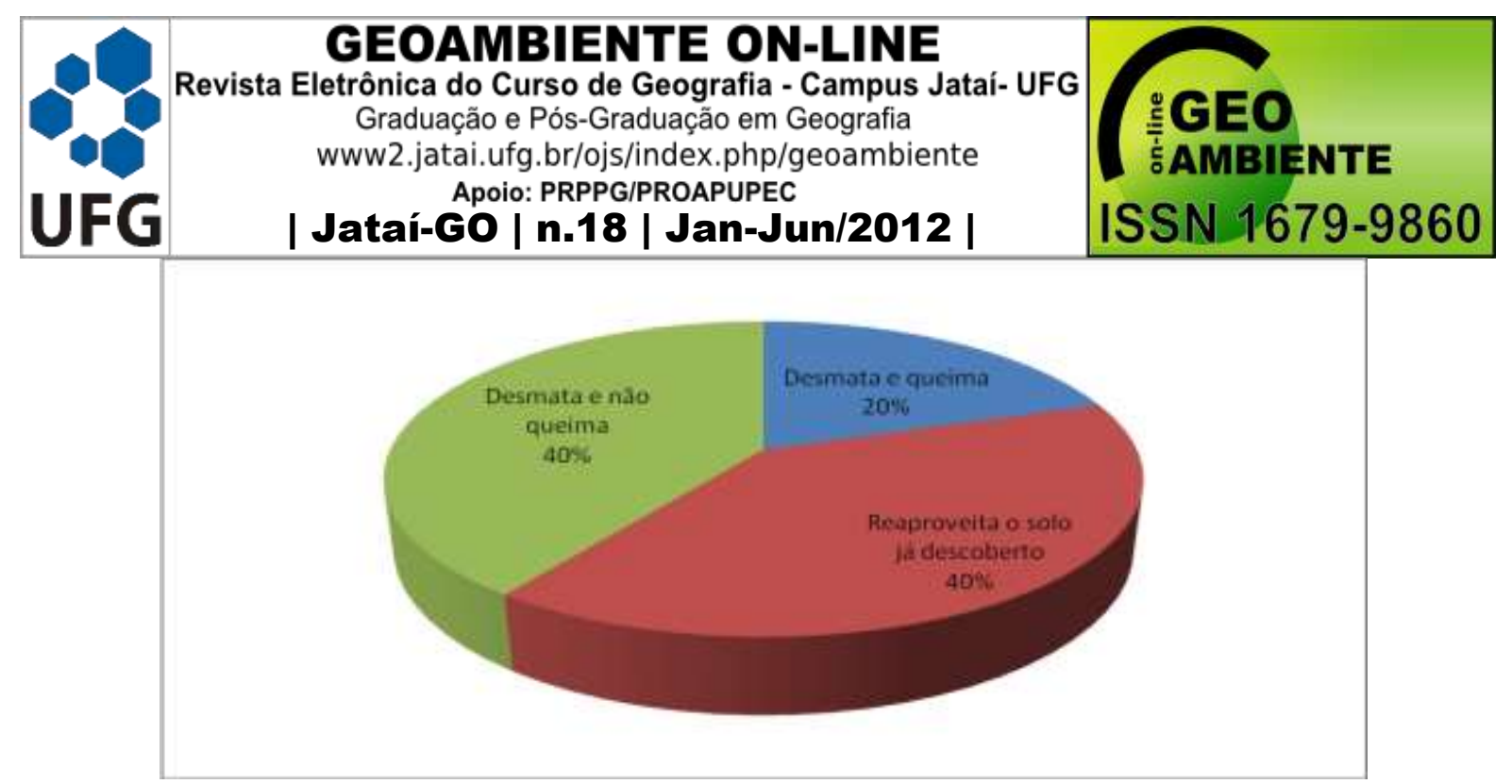

Elaboração própria,2012

O gráfico 3 mostra os principais cultivos citados pelos agricultores estão,feijão, milho,capim,goiaba,banana,gergilim,coco,ortaliças e outros, todos os agricultores entrevistados mesmo entre os que possui renda extra com trabalhos exercidos em outra atividades fora da comunidade, todos trabalha com agricultura mesmo que seja apenas para o consumo doméstico.Mesmo quando não tem inverno eles aproveita as margens do açude que existe na comunidade para fazer seus plantios. Como relata uma agricultora, 42 anos, que reside a mais de 10 anos na comunidade:

No ano que não temos inverno e o açude não enche fica uma área boa aí a gente planta a área descoberta que é dividida para todos assim cada um tem um pedaço de chão para poder plantar mais tudo sem agrotóxico é tudo natural ,teve ano que eu e meu marido tiramos 5 sacos de feijão e no ano que o açude enche aí não plantamos.

Outra agricultora, de 47 anos, que sempre morou na comunidade complementa:

A gente não pode brocar nada nas margem do açude tem que esperar o inverno passar para poder plantarmos, porque na medida que as águas vai baixando aí a gente planta feijão, milho, batata e outros não usa nada é tudo natural faz 8 anos que planto sem usar nada e graça a Deus dar sempre boa colheta só uso esterco de animais para os canteiros e mais nada. 


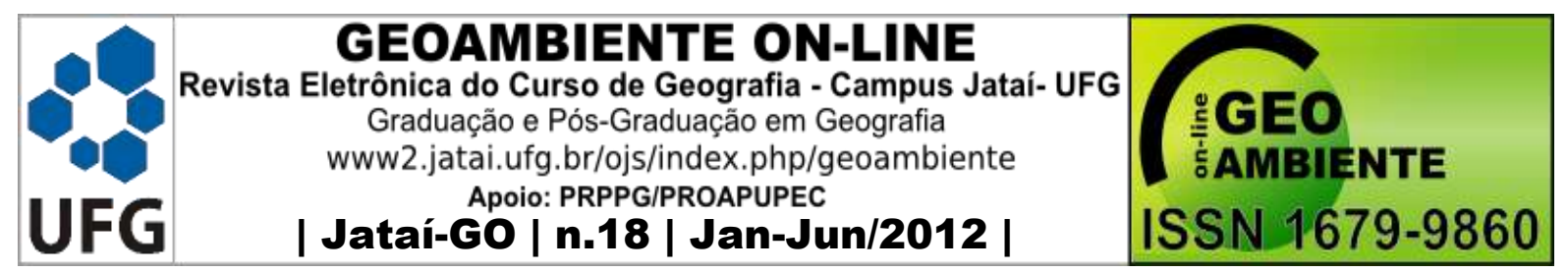

Gráfico3.Principais Cultivos Citados Pelos Intrevistados

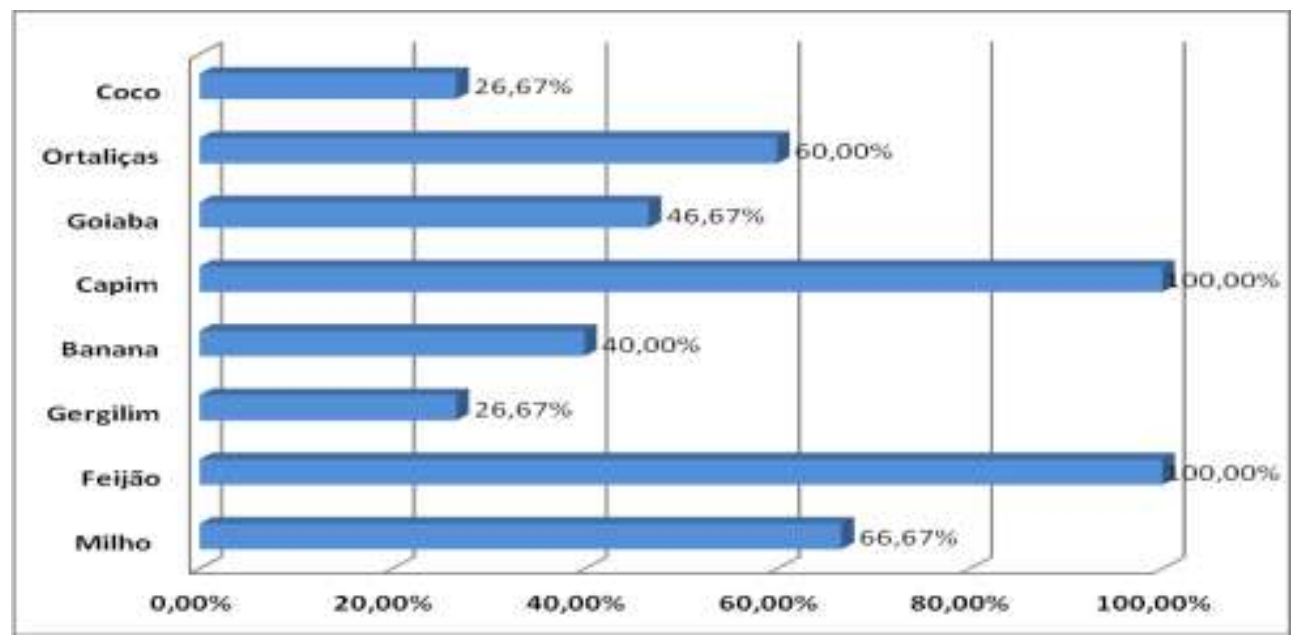

Elaboração própria,2012

Quanto a produção de hortaliças tem 8 famílias que planta o ano todo através do sistema de mandala uma técnica de sistema de irrigação comunitária baseado em canteiros ao redor de um circula de água. Sistema que foi implantado na comunidade pela a CPT nos primeiros anos de assentamento. No inicio a idéia era só para o consumo humano mais com o tempo foi ficando muito excedentes então os moradores decidiram vender esse excedente em feiras agroecológicas na cidade. Como relata uma agricultora que é uma das responsáveis de levar os produtos para vender todas as sextas na cidade de Cajazeiras.

No começo era só para nos mesmo comer mais depois foi sobrando tanto que a vizinha chamou para a gente vender hoje já temos clientes certo levamos tudo aquilo que temos coentro, alface, cebolinha, cenoura, beterraba, rúcula, pimentão e banana, quando as hortaliças estão poucas a gente leva ovo, galinha, doce o que tiver porque não podemos perder os clientes, a nossa maior dificuldade é pouca produção para atender a demanda, no período de chuva a produção cai muito porque a chuva mata as hortas só a parti de maio a setembro temos uma boa produção a parti daí vai ficando muito quente e água que recebemos não é abundante porque são 4 h por dia que recebemos de água, mais primeiro tem que encher as caixas dos banheiros de todos para só depois encher as mandalas fica pouco tempo e água não é suficiente para as hortaliças mesmo assim continuo plantando é minha vida (Agricultura, de 47 anos, que sempre morou na comunidade). 


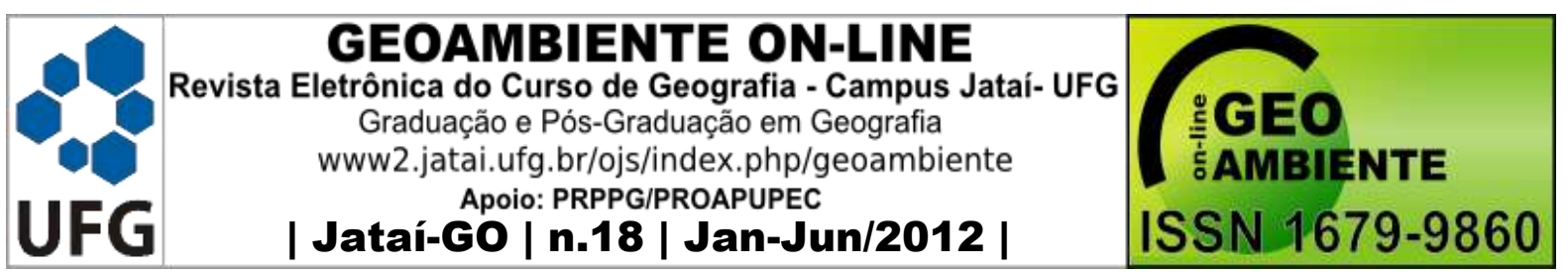

Os agricultores participantes da pesquisa quase todos afirmaram que cria animais para o comércio sendo o preferido o gado segundo eles é tradição desde da fazenda velha em que a principal atividade desenvolvida era a pecúaria extensiva.Hoje a criação é restrita pois cada morador dispõe de 9 hectares de terra para a agricultora e para a criação de animais, gado precisa de muito espaço e pasto, segundo os agricultores o lote é pequeno e $20 \%$ dessas terras tem que ser preservado por isso eles cria em maior quantidade animais como porcos e aves pois estes necessita de um espaço menor.Como mostra o gráfico 4.

Para criarmos pasto para os animais fazemos um banco de proteína dentro do nosso próprio lote, retiramos as plantas menos consumidas por eles como a jurema e marmeleiro e plantamos o trapiá, gliricídia, sabiá, flor de seda, capim, leucena além das nobres que deixamos como aroeira, ipê, juazeiro, angico, catigueira e outras que serve de forragem para os animais no período de estiagem, não é um desmatamento é um manejo retiramos um tipo de vegetação e repomos com outras que sirva de forragem para os animais só assim consiguimos ração o ano todo para os animais(Agricultora, 43 anos, residente a mais de 10 anos na comunidade).

Gráfico 4- mostra os principais criações de animais citadas pelos intrevistados

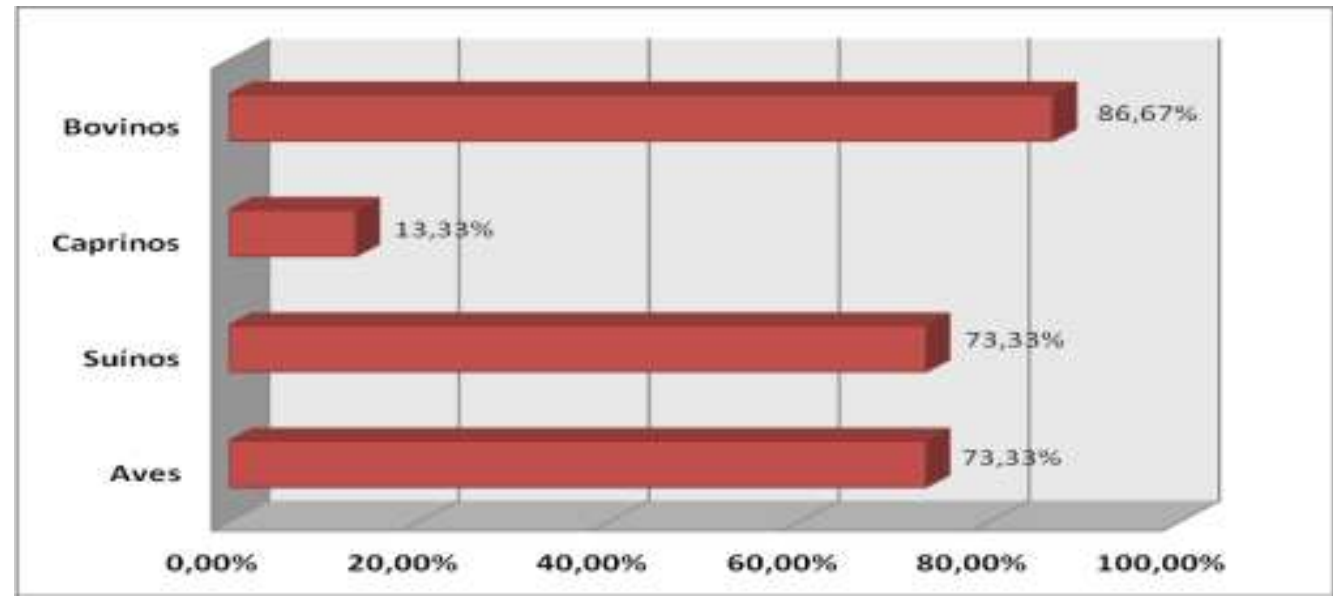

Elaboração própria,2012

Para recuperar o solo degradado o gráfico 5 mostra que a maioria dos agricultores faz reflorestamento de plantas nativas e não nativas numa área comunitária fora do lote onde todos tem que repor lá a mesma quantidade que desmatou em seu lote, além disso eles também faz um manejo dentro do próprio lote. Outros aproveita as áreas degradadas para criatório de abelhas. 


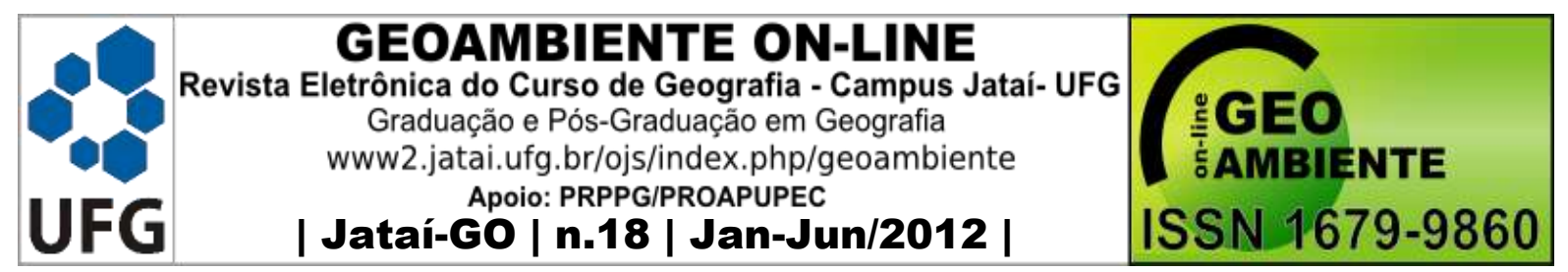

As áreas de tabuleiro desgastado a gente utiliza para colocar as casas das abelhas e ao redor temos que manter a vegetação para poder produzir flores para as abelhas fazer o mel a gente nunca tira as arvóres nobre como; angico, aroeira, mufumbo, marmeleiro, angico, pau d'darco só tira a jurema as vezes o mufumbo mais reflorestamos com sabiá, leucena, gliricídia, trapiá, e outras estamos sempre reflorestando eu mesmo tenho um viveiro de mudas tanto nativas como exótica chego a vender mais de mil mudas para áreas de reflorestamento aqui e fora daqui(Agricultora, de 43anos, que reside a mais de 10anos na comunidade).

Gráfico 5- Os moradores usa o reflorestamento como técnicas de recuperação do solo degradado

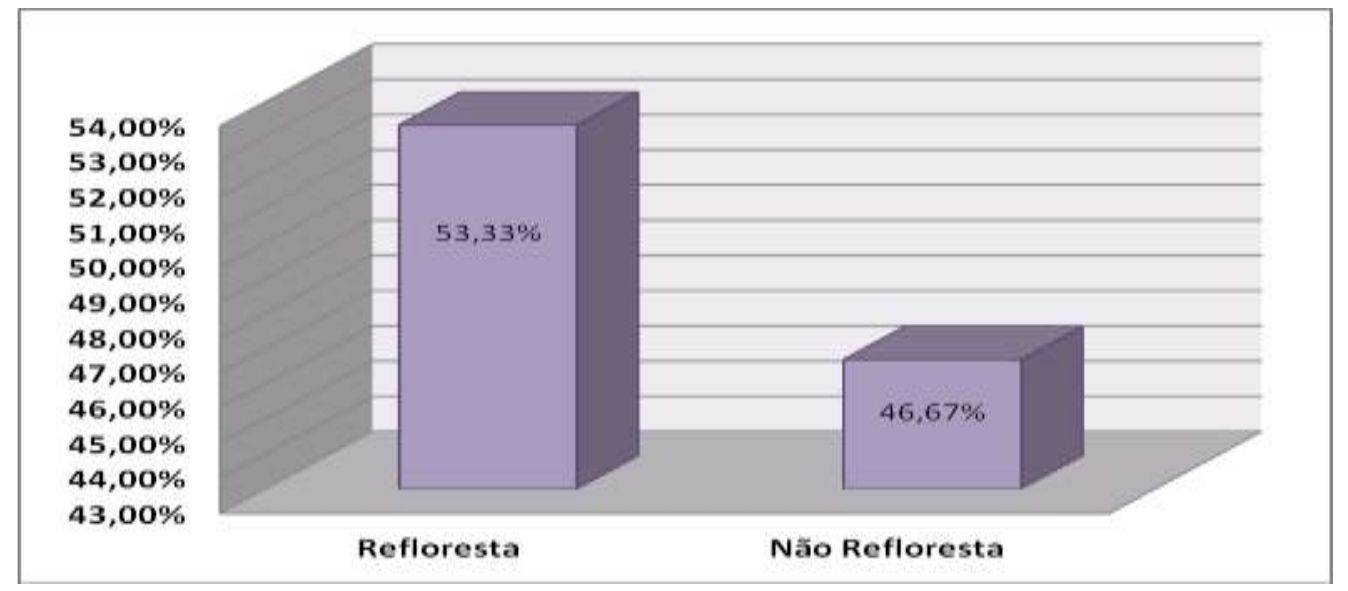

Elaboração própria,2012

\section{CONSIDERAÇÕES FINAIS}

O presente estudo buscou analisar as formas de organização, ocupação e uso do solo no assentamento Santo Antonio, pelo o que foi observado esse uso se dá mediante cultivos de produtos agrícolas e criação de animais. Sendo que boa parte desses solos se destina à pastagem para a criação de animais. De um modo geral, e pelas características da agricultura na área de estudo, foi constatado certo melhoramento desses solos através de práticas de conservação e recuperação, já que é presente o uso de adubação, rotação de cultivos, reflorestamento e a não utilização de agrotóxico nas plantações.

Com a construção do projeto de assentamento, algumas práticas mudaram na área como desmatamento intensivo, caça predatória de animais silvestre e uso abusivo de agrotóxico, práticas estas que era tida como legais antes do projeto de assentamento hoje são praticamente extinta na área. Mais ainda é percebível a resistência de alguns moradores a essas mudanças, são mudanças radicais para quem arrasta raízes de uma cultura que acredita 


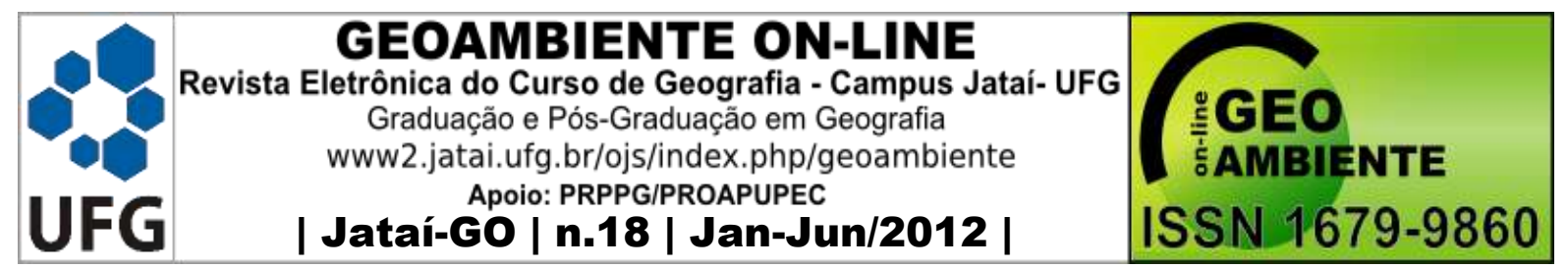

que os recursos naturais são infinitos e estar disponível para a humanidade usufruir. Contrários a este paradigma ONGs e entidades como CPT/Sertão (Comissão Pastoral da Terra-Sertão Paraibano), CAAASP (Associações dos Assentamentos do Alto Sertão Paraibano) AS-PTA (Assessoria e Serviços a projeto de Agricultura Alternativa) ASA BRASIL (Articulação para o Semiárido Brasileiro) e outras presta serviços as comunidades rurais com programas voltados para educação no campo, como a criação de Bancos de Sementes comunitários, manejo da caatinga, criação de abelhas, farmácias vivas, viveiro de mudas, Banco de Proteínas para a criação de animais, agroecologia e outras, são práticas que estão sendo ensinada e trabalhada junto aos agricultores que apreende a cada dia como conviver com o semiárido, quebrando todo aquele paradigma implementado pela agricultura convencional principalmente no tocante ao semiárido, de lugar seco que não produz nada.

É um trabalho que tem que ser contínuo que consistente em mudança de atitude das pessoas em relação aos recursos naturais o trabalho das ONGs e entidades busca conscientizarem os agricultores da importância do solo, da água, da vegetação e dos animais em suas vidas e isso vai sendo conquistado a cada dia pelos os agricultores.

Nessa perspectiva, é um trabalho que busca sensibilizar as pessoas em relação aos problemas do uso, da ocupação e da conservação dos solos e dos recursos naturais em geral. É todo um processo educativo, as experiências e vivências individuais e coletivas são resgatadas e valorizadas em um ambiente de envolvimento afetivo, que favorece a auto-estima individual, de cada agricultor sendo visível a satisfação dos mesmos por se considerar livre de patrões de ter que dividir tudo aquilo que se produzia como relata esse agricultor que viveu na fazenda nos tempos de patrão.

A maioria dos agricultores participante da pesquisa demostaram satisfeitos com as condições de vida no atual assentamento e considera que apesar de passarem por algumas dificuldades e que o assentamneto necessite de certos benefícios, o projeto de reforma agrária trouxe melhoria e mudança de vida para os assentados.

\section{REFERÊCIAS}

ALTIERI, M. Agroecologia: a dinâmica produtiva da agricultura sustentável. 4. ed.- Porto Alegre: Editora da UFRGS, 2004. 


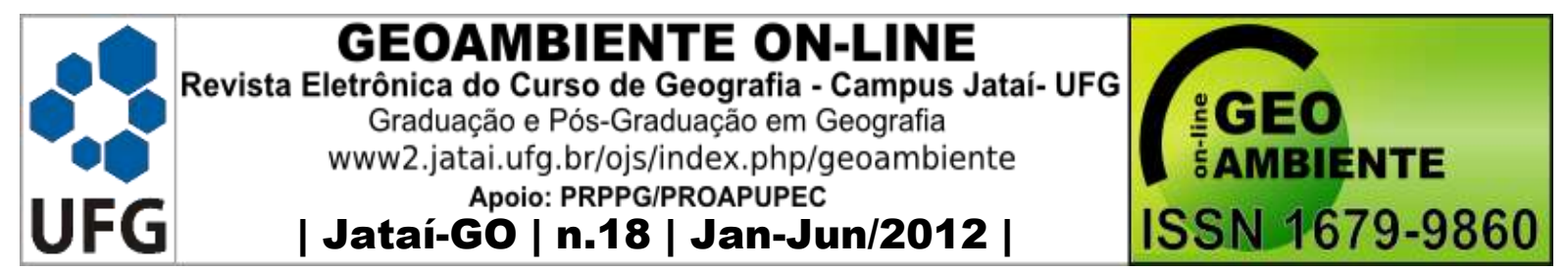

ANDRADE, Manuel. C. de. A terra e o homem no Nordeste: contribuição ao estudo da questão agrária no Nordeste. - 7. ed. rev. E aumenta - São Paulo: Cortez, 2005.

BIERNACKI, P.; WALDORF, D. Snowball sampling-problems and techniques of chain referral sampling. Sociological Methods and Research 10: 141-63, 1981.

BRANCO, Samuel Murgel \& CAVINATTO, Vilma Maria. Solos: a base da vida terrestre. São Paulo: Editora Moderna, 1999.

CAPORAL, Francisco. Roberto. Agroecologia: uma ciência do campo da complexidade / (org.). José Antônio Costabeber. Gervásio Paulus. - Brasília 2009.

CARDOSO, Irene Maria. O Solo Vive. Revista, Agriculturas experiências em agroecologia, Rio de Janeiro, vol. 5, n. 3, setembro. 2008, pg.4-6.

FEITOSA, A. A. F. M. A.; Estudo da percepção dos diferentes grupos ligados ao Parque Ecológico de Engenheiro Ávidos, no município de Cajazeiras - PB. 2000. 86 f. Dissertação (Mestrado) - Universidade Federal da Paraíba, João Pessoa - PB, 2000.

GOMES N. M., Manoel A. de Faria; Antônio M. da Silva; Carlos R. de Mello; Marcelo R. Viola. Variabilidade espacial de atributos físicos do solo associados ao uso e ocupação da paisagem. Rev. bras. eng. agríc. Ambient, Campina Grande, v.11, n.4, jul./ago. 2007.

GUERRA, Antonio José Teixeira \& CUNHA, Sandra Baptista da. (org). Geomorfologia: uma atualização de bases e conceitos. São Paulo: Bertrand Brasil, 1995.

LAKATOS, E. M.; MARCONI, M. de A. Fundamentos de Metodologia Científica. 6. ed. São Paulo: Atlas 2005. 315 p.

MICHAELIS. Moderno Dicionário da Língua Portuguesa. São Paulo: Companhia Melhoramentos, 1998.

MINAYO, M. C. de S. O Desafio do Conhecimento: Pesquisa Qualitativa em Saúde. 5. ed. São Paulo: Hucitec-Abrasco, 1998. 269 p 


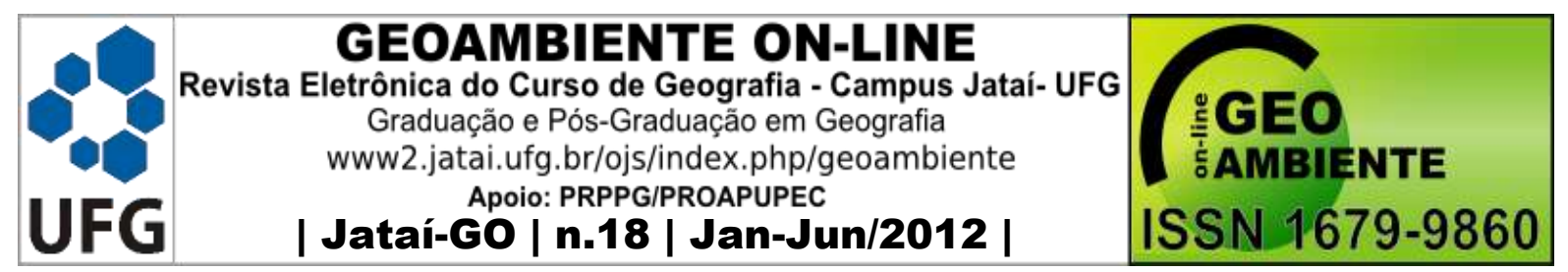

MOTA, Suetônio. Preservação e Conservação de Recursos Hídricos. $2^{\mathrm{a}}$ ed. Rio de Janeiro: ABES 1995.

MUGGLER, Cris Carole. Fábio de A. P. Sobrinho, Vinícius A. Machado. Educação em solos: princípios, teoria e métodos. Rev.Bras.Ciênc. Solo, Viçosa, vol.30, n.4, jul/ago. 2006.

PEREIRA Jógerson Pinto Gomes. Curso Fundamentos da Agroecologia; Especialização em desenvolvimento sustentável para o Semi-Árido Brasileiro; UNIDADE ACADÊMICA DE ENGENHARIA AGRÍCOLA / UFCG; Associação Brasileira de Ensino Agrícola Superior ABEAS. Setembro - 2005.

PETERSEN, Paulo. Edinei de Ameilda. Revendo o conceito de fertilidade: Conversão ecológica do sistema de manejo dos solos na região do Contestado. Revista, Agriculturas experiências em agroecologia, Rio de Janeiro, vol. 5, n. 3, p.16-23, setembro. 2008, pg.16-23.

PRIMAVESI, Ana Maria. Agroecologia e manejo do solo. Revista, Agriculturas experiências em agroecologia, Rio de Janeiro, vol. 5, n. 3, p.7-10, setembro. 2008, pg.7-10.

SOUZA, A. H. F. F. Açude Jatobá I, Patos-PB: Colonização de invertebrados, usos e percepção ambiental dos atores sociais do seu entorno. Dissertação (Mestre em Desenvolvimento e Meio Ambiente), Universidade Federal da Paraíba, João Pessoa-PB. 2009.

http://www.fae.edu/publicacoes/pdf/IIseminario/pdf_reflexoes/reflexoes_26.pdf Acesso em: $11 / 10 / 2011$ às $20 \mathrm{~h} 36 \mathrm{~min}$

http://www.ibge.gov.br/cidadesat/link.php?uf=pb Acesso em: 09/10/2011 